\title{
Simulation of Range Safety for the NASA Space Shuttle
}

\author{
Luis Rabelo, Jose Sepulveda, Jeppie Compton, and Robert Turner
}

\begin{abstract}
This paper describes a simulation environment that seamlessly combines a number of safety and environmental models for the launch phase of a NASA Space Shuttle mission. The components of this simulation environment represent the different systems that must interact in order to determine the Expectation of casualties $\left(E_{c}\right)$ resulting from the toxic effects of the gas dispersion that occurs after a disaster affecting a Space Shuttle within 120 seconds of lift-off. The utilization of the Space Shuttle reliability models, trajectory models, weather dissemination systems, population models, amount and type of toxicants, gas dispersion models, human response functions to toxicants, and a geographical information system are all integrated to create this environment. This simulation environment can help safety managers estimate the population at risk in order to plan evacuation, make sheltering decisions, determine the resources required to provide aid and comfort, and mitigate damages in case of a disaster. This simulation environment may also be modified and used for the landing phase of a space vehicle but will not be discussed in this paper.
\end{abstract}

Key words: NASA Space Shuttle, Safety Managers, Expectation of Casualties, Simulation, Range, Geographical Information Systems

\section{Introduction}

During a space launch, range safety is tasked with ensuring the safety of the public, the astronauts, the workforce and the equipment/facilities in that order. To prepare for a potential disaster, safety managers need to determine the population at risk. Decision-support systems based on computer simulations can enable safety managers to determine mitigation projects, and better understand the different risks associated with operations. For example, if toxic gases are released, there is a need to predict where the gas plume will go, how far it will extend, the expected concentration of toxins, and the health and safety consequences. 
To assist in the decision making process, this team developed a Virtual Range system that is a prototype of a simulation environment. The purpose is to study the safety criteria for National Aeronautics and Space Administration (NASA) current and next generation space vehicles during range operations with emphasis on toxic releases during launch. This effort involved the development of a unique collaborative computing environment where range safety simulation models, geographic information systems (GIS), and weather information systems are hosted and integrated in a seamless fashion with parametric features of space vehicles and their flight trajectories, and a probabilistic calculator/simulator to compute the Expectation of casualties $\left(\mathrm{E}_{\mathrm{c}}\right)$ (see Figure 1).

Insert Figure 1 (See end of article)

The range operations is an essential element of space operations. For the purpose of this research, the range is considered to be the volume through which the space vehicle must pass on its way to and from space, and its projection on earth. The range encompasses many different operations (security, weather, facilities, vehicle processing, and safety); like many of the operations, range safety has a high level of complexity. One of range safety's major concerns is the safety of the people within the projection of the range volume onto the earth's surface that may be exposed in the event of a disaster. The actual dimensions of the volume and its projection onto the surface depend on the vehicle's speed and direction. As the space vehicle moves, the range encompasses new volumes and leaves behind areas that fall out of range of potential hazards. 
The range safety office's responsibilities include the study, modeling, and analysis of the hazards from potential launch accidents and the corresponding calculations of $E_{c}$. Toxic effects, debris, and blast overpressures and their effects on the population are the primary hazards to be studied. The solid rocket booster (Figure 2) fuel on many of today's space vehicles as well as the resulting exhaust emissions may cause toxic effects. Vehicle explosions caused by system failures produces debris and may also create a blast overpressure. Modeling of these effects can take considerable time. Therefore, the seamless integration of these safety models with flight trajectories, available weather information, and GIS systems can provide many benefits. Hosting the range models and vehicle models in a computer simulation environment will support the development of risk management and reduce risk avoidance approaches. For example, a Virtual Range can be used to design and evaluate Flight Termination Systems (FTS), and to evaluate and implement a safety assessment scheme for both legacy and new space vehicles.

Insert Figure 2 (See end of article)

Since the application of the Virtual Range can be so broad, we decided to focus on the goal of determining the $E_{c}$ of the population at risk to exposure to a toxic gas dispersion resulting from a potential disaster within 120 seconds of a Space Shuttle liftoff. The system can assist safety in estimating the population at risk in order to plan for areas to shelter, evacuate, and/or for the resources required to provide aid and comfort and mitigate damages. Toxic gas-related risk is a factor of exposure duration and toxic propellant concentration or dosage that would result in casualties ("Casualty is considered to include either death or injury, of at least 1-day disability, from the direct effects of an accident" (Anderson and McCaleb, 2004) to normal and sensitive 
people in a given population area. For the purpose of this paper, the focus is on the health impact of the release of large amounts of Hydrochloric Acid $(\mathrm{HCl})$, a major combustion bi-product and major toxicant.

\section{The Virtual Range's Architecture}

The Virtual Range integrates Geographic Information Systems (GIS), a population model, a gas dispersion model, Space Shuttle flight trajectory and reliability and failure models, and weather data. The architecture is modular so that it can be easily applied to any space vehicle models and/or launch operation areas.

Monte Carlo simulation - a technique that repeatedly generates random values for uncertain variables to simulate a model - accounts for the effects on risk factors such as vehicle position and consumption of propellants, weather uncertainties, vehicle guidance, and vehicle performance deviations. The need for a simulation of these factors is paramount. For example, toxic gas impact risk is affected by variability in the meteorological and launch vehicle parameters, wind uncertainties, and other weather related characteristics. Monte Carlo simulation is also used to determine the launch decision. For any planned flight path, safety needs to determine the $E_{c}$ using the actual conditions (input parameters). These analyses will identify parameters with the largest impact on the value of Ec and, therefore, identify where modeling accuracy is most critical. 
If an accident occurs, the Virtual Range system determines the position of the space vehicle, the impacted volume, weather data and its trends, and initial dispersion velocity of the released pollutants. These values are the input to the Virtual Range dispersion model called CALPUFF (Earth Tech, 1997; Earth Tech, 2002) a multi-layer, multi-species, non-steady state Lagrangian puff dispersion model - which in turn predicts the toxic concentrations of the toxicant at a specified time after the onset of the accident. These values determine the envelope over land where the pollutant concentration exceeds the ceilings imposed by the pollutant's Exposure Response Functions (ERFs). We use the number of exposed people under that envelope to estimate the number of casualties resulting from exposure to toxic levels of the released toxic propellant for that simulated disaster.

For the $\mathrm{E}_{\mathrm{c}}$ calculation restricted to gas dispersion, we focused on displaying boundaries. We used as a critical value the concentration defined for an $E_{c}$ of $30 \times 10-6$ casualties/launch (i.e., 30 casualties per million flights), resulting from a number of legal decisions related to carcinogens causing cancer and generally accepted for the United States Federal Aviation Administration (FAA). Anderson and McCaleb (2004) state that "this criterion was derived from the principle that the ranges should be operated in a manner that is as safe to the public as general or commercial aviation." However, this principle is being changed to one that says the launch must be no more hazardous than day-to-day operations.

\section{Factors Affecting $E_{c}$}


This section focuses on the factors that may affect the computation of $E_{c}$.

\section{Flight Path}

For a planned flight path trajectory (altitude, speed, direction), the system projects an appropriate "envelope" (i.e., the footprint of the projected impact) for a given risk-component. We focused on released toxic gases and used the CALPUFF model to predict their path and concentration levels.

Figure 3 displays the typical launch sectors for launches from the Eastern Range (Cape Canaveral Air Force Station and Kennedy Space Center (KSC); owned or leased facilities on downrange sites such as Antigua and Ascension; and in the context of launch operations, the Atlantic Ocean, including all surrounding land, sea, and air space within the reach of any launch vehicle extending eastward into the Indian and Pacific Oceans). In general, space vehicles are launched in an easterly direction and on an azimuth that provides protection of land masses and populated areas on and off the facility, including the Caribbean Islands, Bermuda, the Northeast coasts of South America, and Africa. For polar launches from Cape Canaveral the azimuth upper limit is $37^{\circ}$ and the lower limit is $44^{\circ}$. For equatorial launches, the azimuth upper and lower limits are $110^{\circ}$ and $114^{\circ}$, respectively. Therefore, the first factor that may be significant is the direction (polar, equatorial) of the launch.

Insert Figure 3 (See end of article) 


\section{Probabilities of Failure for the Space Shuttle}

The second factor is the exact location where the accident occurs. The Virtual Range interface grants the safety official the ability to select a random occurrence for the accident or to "fix" the time or location of the accident. There is also a third time-related option, which is to specify a series of observations at fixed time intervals (for example, at $0,10,20,30$, etc. seconds after launch). Monte Carlo simulation works by generating random numbers based on the probabilities of certain events occurring which are obtained from a comprehensive reliability model developed for NASA (Fragola and Maggio, 1995). This reliability model presents the total probability of losing the space vehicle due to the failure of the different Space Shuttle systems and subsystems (see Figure 4). In order to obtain the probability of losing the vehicle at the different stages during the first 120 seconds we divided that period of time into representative events that depict a range of time for which we calculated the probability of losing the vehicle as a result of an issue within one of the main components such as the external tank, space shuttle main engine, integrated solid rocket booster, and orbiter (see Figures 2 and 5).

Insert Figure 4 (See end of article)

With the intention of getting a better estimate of the probability at the different stages, Space Shuttle experts were asked to assign weights to represent their best estimate for a failure occurring in a given subsystem during the Space Shuttle operation. With this information the total probability was weighted and calculated at each stage within the first 120 seconds.

Insert Figure 5 (See end of article) 


\section{The Toxicity Model}

The Space Shuttle relies upon two Solid Rocket Boosters (SRBs) to launch the Space Shuttle into space. The SRBs contain aluminum powder as fuel and ammonium perchlorate as its oxidizer. Hydrochloric acid $(\mathrm{HCl})$ is a major combustion bi-product. Due to its relative high quantity; the expected direction and concentration of the dispersion of $\mathrm{HCl}$ gas is a major determinant considered during launch decisions. During normal operation the total exhaust of $\mathrm{HCl}$ is 163.3 tons during the first 15 kilometers of flight. About 72.5 more tons are exhausted at higher altitudes in the first two minutes after launch (American Institute of Aerospace and Astronautics, 1992). If a "loss of vehicle" event occurs close enough to lift-off, it is possible under some meteorological conditions that the ground concentration would exceed $7 \mathrm{ppm}$, which is the short-term exposure limit (STEL) for $\mathrm{HCl}$ for normal people (Hill Brothers Chemical Company, 2001).

Exposure to the HCL gas for normally healthy persons can vary by location and the reaction to the exposure can vary from mild to severe by individual. Mild $\mathrm{HCl}$ exposure symptoms include irritation and headache, which are reversible within 48 hours and do not interfere with normal activity or require medical attention (Philipson, 1999). Moderate symptoms include cough and shortness of breath, and medical attention might be necessary. Severe symptoms include disorientation due to constriction of the airway and consequent shortfall in delivery of oxygen to the brain; changes to lung tissue are irreversible in this category. Of course, the STEL values for sensitive people (children, the elderly, and people with asthma or other respiratory diseases) are even smaller and very difficult to predict. 


\section{The Gas Dispersion Model.}

For the evaluation of the gas dispersion and toxic effect we use CALPUFF, a model developed and distributed by Earth Tech (2002). CALPUFF simulates the effects of time and space by varying meteorological conditions on pollutant transport, transformation, and removal under inhomogeneous and non-stationary conditions. CALPUFF has modules to assess toxic effects of specific chemical agents and factors such as variability of meteorological conditions, dry deposition and dispersion over a variety of spatially varying land surfaces, low wind speed dispersion, or wet removal of the pollutant.

There are several factors associated with CALPUFF that may affect the value of $\mathrm{E}_{\mathrm{c}}$, the most important of which are the initial speed of the toxic plume, the weather conditions (humidity, temperature, pressure, etc.), the wind speed and direction.

The Weather Factor. CALPUFF has been accepted by the US Environmental Protection Agency (EPA) as a guideline model used in all regulatory applications involving the long-range $(>50 \mathrm{~km})$ transport of pollutants. It can also be used on a case-by-case basis in situations involving complex flow and non-steady-state cases from fence-line (near field) impacts out to $50 \mathrm{~km}$. The model includes three main components (models): CALMET, CALPUFF, and CALPOST. In addition, it also includes several pre-processing programs to interface the model to standard, routinely-available, meteorological, and geophysical datasets. 
CALMET is a meteorological model that develops hourly wind and temperature fields on a three-dimensional grid modeling domain with associated two-dimensional fields such as mixing height, surface characteristics, and dispersion properties. Selected temporal and spatial variations in the meteorological fields are explicitly incorporated in the resulting distribution of puffs throughout a simulation period.

CALPUFF contains algorithms for near-source effects such as building downwash, transitional plume rise, partial plume penetration, and sub-grid scale terrain interactions, as well as longer range effects such as pollutant removal (wet scavenging and dry deposition), chemical transformation, vertical wind shear, over-water transport, and coastal interaction effects. It can accommodate arbitrarily-varying point source and grid area source emissions. Most of the algorithms contain options to treat the physical processes at different levels of detail depending on the model application. The primary output files from CALPUFF contain either hourly concentrations or hourly deposition fluxes evaluated at selected receptor loçations.

CALPOST is used to process the output files produced by CALPUFF. In addition, CALPOST summarizes the results of the simulation.

Meteorological Surface Data. The meteorological surface observations are obtained from the National Oceanic and Atmospheric Administration (2004). These meteorological data files contain near real-time observations of: wind speed, wind direction, temperature (part of surface data file), cloud cover, ceiling height, surface pressure, relative humidity, and precipitation type code. 
To improve the accuracy, given the position and code of the station, the meteorological surface data acquires information from nearby weather stations. We used the data from four different stations near Kennedy Space Center.

Upper Air Data. This set of observations contains observed vertical profiles of: wind speed, wind direction, temperature, pressure, and elevation. The data is obtained from from NOAA's Radiosonde Database Access (National Oceanic and Atmospheric Administration, 2004). Geophysical Data. This data file contains the geophysical data inputs required by the CALMET model. These inputs include: grid fields of terrain elevations, land use categories, surface roughness length, albedo, bowen ratio, soil heat flux constant, anthropogenic heat flux, and vegetative leaf area index.

Over-water Data. This data is necessary to know the Over-water transport and dispersion. For this purpose it is necessary to have the following information: air-sea temperature difference, air temperature, relative humidity, over-water mixing high, and wind speed and direction. The location of the over-water site is specified for each observation. The information is taken from the closest buoy, in this case Station 41009 - CANAVERAL which is located 20 nautical miles East of Cape Canaveral. This information is obtained from the National Data Buoy Center, a division of the National Oceanic and Atmospheric Administration (National Data Buoy Center Unedited Surface Weather Observations, 2004).

\section{Geographic and Population Models}

The Virtual Range uses ArcGIS - a commercial GIS application from ESRI Corporation that provides data visualization, query, analysis, and integration capabilities along with the ability to create and edit geographic data (ESRI, 2004) - to identify the region covered by the dispersed 
gas. The area covered in our simulation is basically the area around the Cape Canaveral region, which includes Brevard and Orange Counties (Florida, USA) and a large part of the sea around Cape Canaveral. The simulation covers about 150 kilometers in each direction from the source (Cape Canaveral). Since this area around Cape Canaveral is a flat, noncomplex terrain and surrounded by sea, the weather data plugged into the model plays an important role in the simulation. It has a good flow of winds along with pressure and temperature variations across it. The area covered by the simulation is divided into a number of grids with equal spacing to facilitate the study of concentrations resulting from a normal launch or from explosions in the area considered. Each grid can be a square block, whose side can range from 10 s of meters to 100 s of kilometers.

The Virtual Range determines the population at risk for that specific risk-component using the LandScan Global Population Database, a public domain database of the world's population developed by the Oak Ridge National Laboratory (ORNL), to present population data associated within the covered region (Oak Ridge National Laboratory, 2004). LandScan includes the best available census counts (usually at province level) for each country and allocates these figures into rural and urban population distributions on a $30^{\prime \prime}$ X 30 " lat/long grid cell system. To assign values to a specific grid cell, LandScan calculates a probability coefficient for each cell and applies the coefficients to the census counts. The probability coefficient is based on slope, proximity to roads, land cover, night-time lights, and an urban density factor.

\section{Exposure Response Functions}

Figure 6 shows the Exposure Response Functions (ERFs) for $\mathrm{HCl}$ for sensitive and normal people subject to a 30-minute exposure. The sensitive population was defined as children 
through age 14 and adults aged 75 and over, as well as all others with respiratory illnesses. In Brevard County, recent census data shows that $42 \%$ of the population is composed of those either 18 and younger or 65 and older; this number is expected to increase to about $55 \%$ by the year 2010 (United Way of Brevard County, 2002). These curves show that concentrations of 15 ppm and $41.5 \mathrm{ppm}$ of $\mathrm{HCl}$ result in an expectation of casualties of about 30 in a million launches $\left(E_{c}=30 \times 10^{-6}\right)$ for sensitive and normal people, respectively.

\section{Insert Figure 6 (See end of article)}

ERF curves have been computed for nitric acid, nitrogen dioxide, and hydrochloric acid (Philipson, 1999). They were constructed by a panel of about 20 expert toxicologists who provided best estimates of the 1 and 99 -percentiles of expected casualties. Below the first percentile, "essentially no one in a population of a given sensitivity category would be affected to a given level of severity." Above the 99th percentile, "essentially all in the population would be so affected." Twelve estimates (with ranges of uncertainty) for each substance and duration of exposure $(10,30,60$, and 120 minutes $)$ were provided by members of the panel of experts: one for each percentile, casualty type (mild, moderate, and severe), and victim type (sensitive, normal). Some of the panelists computed duration estimates from 1-hour estimates according to Haber's Law, which states that "an effect level is directly proportional to exposure concentration multiplied by time" (Philipson, 1999). Once these estimates were decided upon by the panel, ERF curves were then calculated as cumulative distributions.

\section{Geographic Data Model}


ArcGIS is used along with LandScan Global Population Database. In this GIS environment, the model of population distribution is integrated with the gas dispersion model to calculate $\mathrm{E}_{\mathrm{c}}$ for that risk component given there is a loss of the space vehicle. Spatial Analyst, an extension toolset in ArcGIS, is used to generate the query on the $\mathrm{HCl}$ data from the Gas Dispersion Model to select the region where the concentration of the $\mathrm{HCl}$ exceeds a critical value (see Figure 7).

Insert Figure 7 (See end of article)

Note that Spatial Analyst and LandScan combine to give an estimate of the number of people that may be exposed in the affected area. However, this figure represents an upper limit for the number of people at risk as some people will undoubtedly be able to take cover or flee the region before the gas dispersion reaches it. Still a sensitivity analysis could be done on the proportion of the exposed people that will actually die or be incapacitated as a result of the accident.

\section{Summary and Conclusions}

The Virtual Range system in summary work as follows: A discrete-event simulator simulates the time of accident, which is determined by the cumulative probability of an accident occurring in different stages of a launch. Each of these stages has a different duration and chance of accident. Based upon the time of the accident, the model references coordinates for the path of the space vehicle and determines the volume of remaining pollutants from the existing model data file. These values are the input to CALPUFF, which in turn predicts the toxic concentrations for each toxicant at hourly intervals. These values are entered automatically as a layer into ArcGIS, to 
determine the envelope over land where the pollutant concentration exceeds the ceilings imposed by the corresponding ERF. ArcGIS's Spatial Analyst has the ability to determine the number of people covered by the displayed layer. We use the number of exposed people and the parameters resulting from the pollutant's ERF to estimate the number of casualties for a simulated disaster resulting in exposure to toxic levels of the released toxicant. Repeating the procedure through enough simulation runs, we can get enough information to generate an "average" boundary and its associated confidence interval.

Table I presents an example of the selected results obtained. In our initial results, the sensitivity analysis shows that wind direction and the time of accident (seconds after launch) have the most significant impact on the number of people on the ground exposed to dangerous concentrations of the toxicant after the onset of the disaster. In these runs, however, we varied wind directions from $0^{\circ}$ to $360^{\circ}$ in increments of $45^{\circ}$. In the final runs the limits for variations in wind direction will be given by the extreme values observed on actual launch dates.

Insert Figure 8 (See end of article)

In conclusion, the Virtual Range develops a prototype of a virtual engineering environment that focuses on the first two minutes after lift-off. The scope for $E_{c}$ calculation is restricted to toxic gas dispersion. Toxic gas-related risk is a factor of exposure duration and toxic propellant concentration or dosage that would result in casualties of normal and sensitive people in a given population area. The Virtual Range's easy-to-use, "intuitive" interface provides numerical and 
graphical summaries of potential outcomes, with user-defined preferences for the display of units of measure, geographic locations, and time values.

The factors we selected for an in-depth sensitivity analysis of the population at risk, included the space vehicle trajectory, accident location, vehicle position and consumption of propellants, weather and wind uncertainties, and amount and type of toxicants released. Such factors may significantly affect the computation of the population exposed and the corresponding expectation of casualties resulting from the toxic effects of the gas dispersion occurring after a disaster affecting a Space Shuttle within 120 seconds of lift-off.

The modular architecture of the Virtual Range allows for the analysis of new vehicles (e.g., the Crew Exploration Vehicle being designed for NASA for the exploration of the Moon and Mars (National Aeronautics and Space Administration, 2004)) and the study of other launching sites. In addition, we are in the process of integrating debris and blast models. As a result, safety managers could know more about the number of casualties (fatalities, serious and slight injuries, and uninjured) and the level of damage to buildings and facilities for different scenarios.

\section{References}

Anderson, J., McCaleb, R. (2004), Toxic Gas Exposure Risks Associated with Potential Shuttle

Catastrophic Failures, NASA Technical Report 2004-213284.

American Institute of Aeronautics and Astronautics (1992), Atmospheric Effects of Chemical Rocket Propulsion, AIAA Publications.

Earth Tech (1997), User Manuals for CALPUFF Version 5, Boston, Massachusetts. 
Earth Tech (2002), Addendum for CALPUFF Version 6, Boston, Massachusetts.

ESRI (2004), http://www.esri.com/.

Federal Aviation Administration AST Office (2002), Operating in the Federal Ranges, Student

Training Guide, Safety Inspector Training and Qualification Program.

Fragola, J., Maggio, G. (1995), Probabilistic Risk Assessment of the Space Shuttle. Phase 3: A Study of Potential of Losing the Vehicle during Nominal Operation, Vol. 2: Integrated Loss of Vehicle Model. Report, report submitted by SAIC (Science Applications International Corporation) to NASA.

Hill Brothers Chemical Company (2001), Material Safety Data Sheet. Available http://hillbrothers.com/msds/pdf/hydrochloric-acid-solution.pdf.

National Aeronautics and Space Administration (2004), Crew Exploration Vehicle (CEV) Procurement. Available http://exploration.nasa.gov/acquisition/cev procurement.html.

National Data Buoy Center Unedited Surface Weather Observations (2004), http://www.nndc.noaa.gov/cgi-bin/nndc/buyOL001.cgi?FNC=qcall__Aswoqmain_htm.

National Oceanic and Atmospheric Administration (2004), Available http://www.ndbc.noaa.gov/station page.phtml?station=41009.

Oak Ridge National Laboratory (2004), LandScan. Available http://sedac.ciesin.org/plue/gpw/landscan/.

Philipson, L. (1999), An expert elicitation of estimates of exposure limits for space and missile launch toxicants, NASA Technical Report No. 99-400/11.2-01.

United Way of Brevard County (2002), Report of Population. Available http://www.uwbrevard.org/news/newsbustour.htm. 


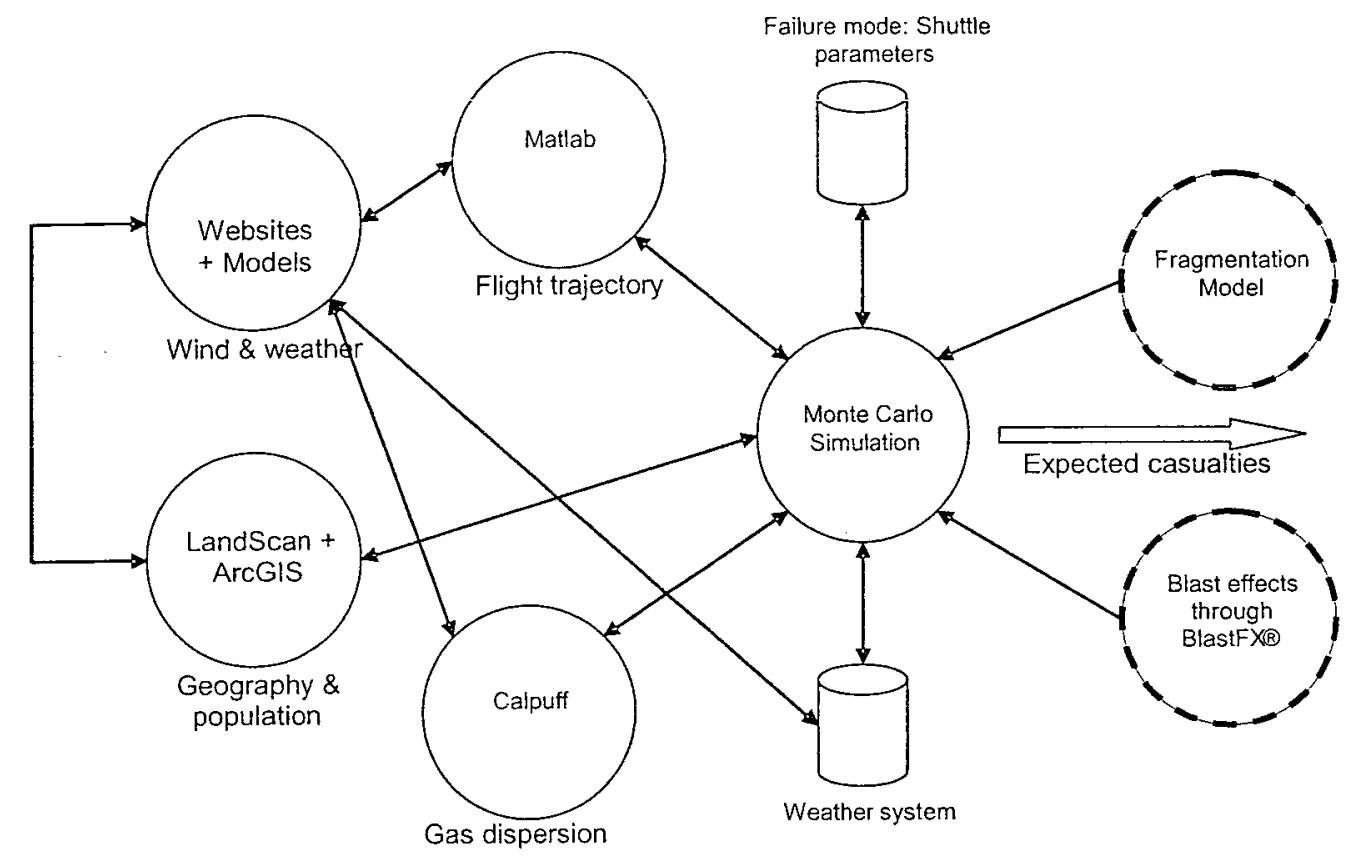

Figure 1. The Virtual Range and its modules (the fragmentation and blast capabilities are currently being added). 


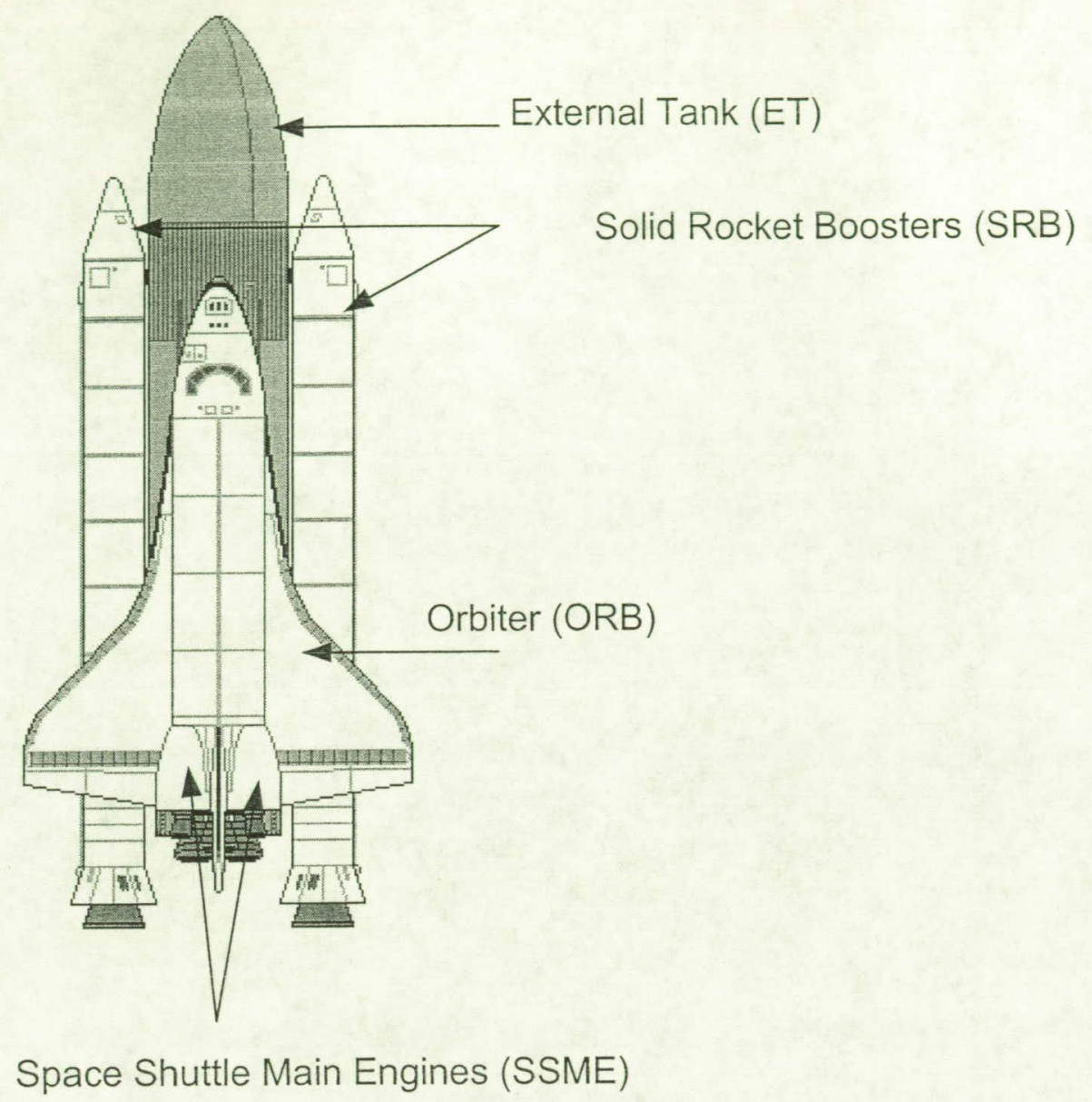

Figure 2. The NASA Space Shuttle and its main components (NASA has three shuttles: Discovery, Atlantis, and Endeavour). 


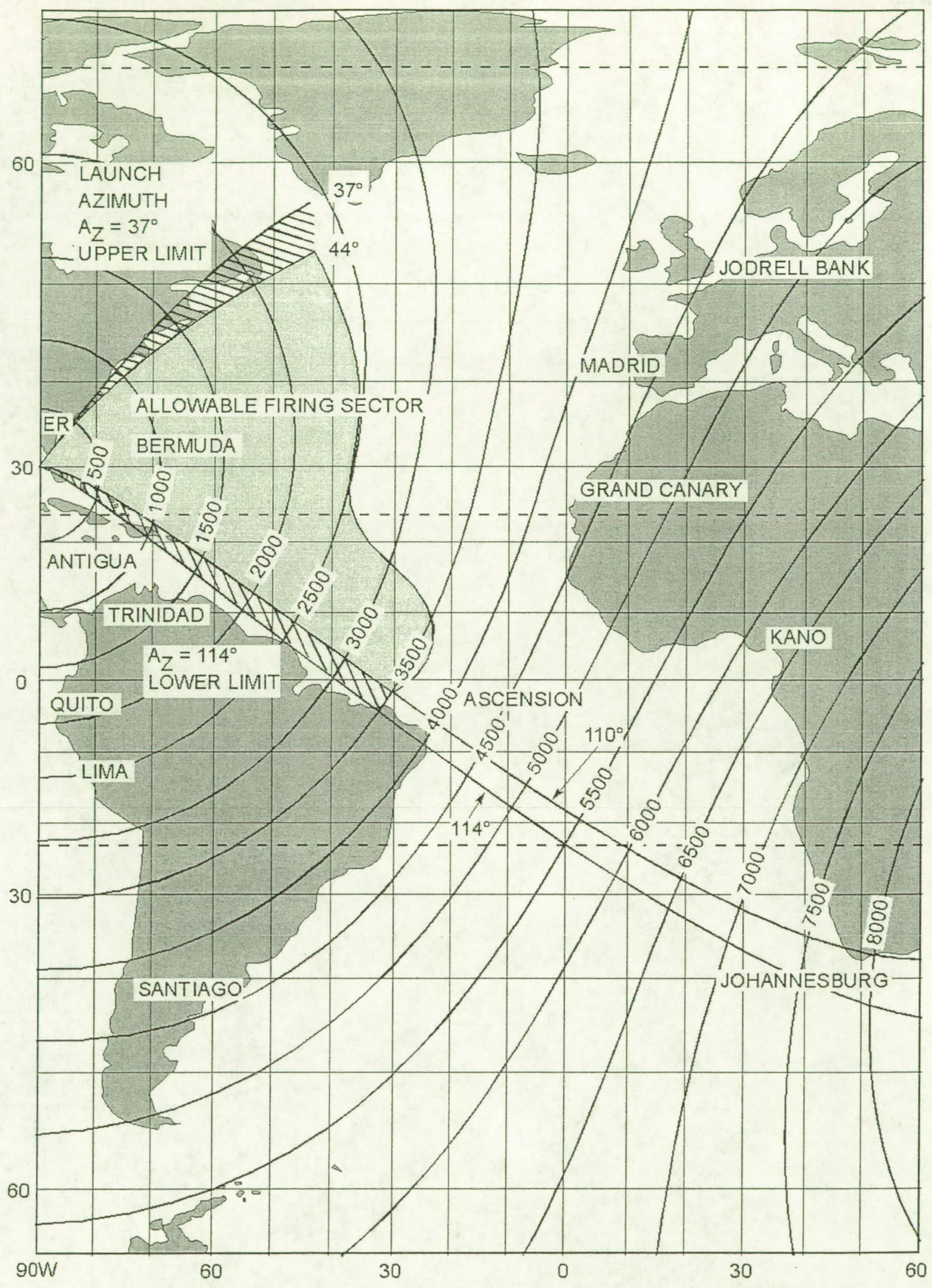

Figure 3. Two different flight paths (adapted from the Federal Aviation Administration AST Office (2002)). 


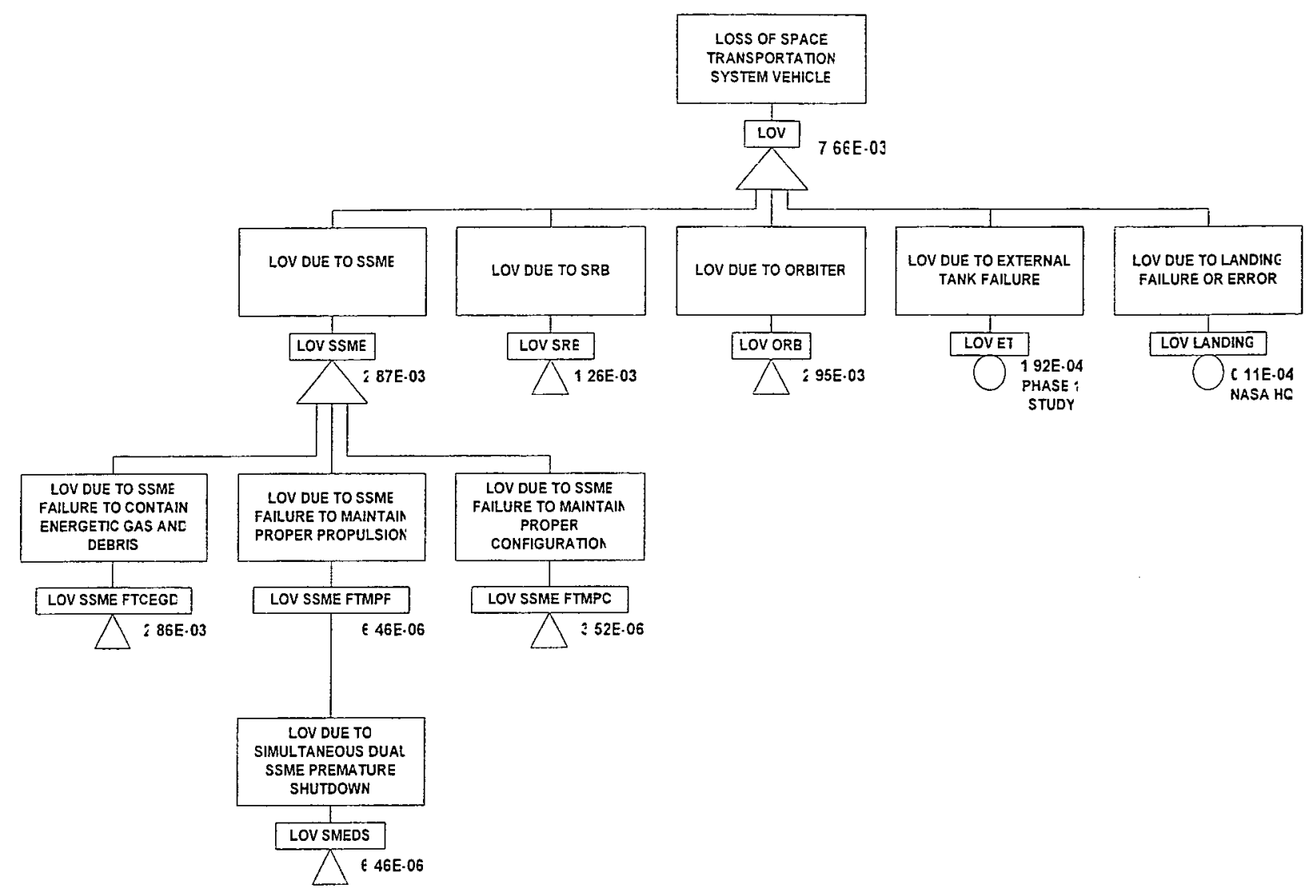

Figure 4. Top of the failure tree adapted from the reliability study of Fragola \& Maggio (1995) (Page 1) where LOV is lost of vehicle, SSME is Space Shuttle Main Engines, SRB is Solid Rocket Boosters, ORB is Orbiter, ET is External Tank, FTCEGD is Failure to Contain Energetic Gas and Debris, FTM $\bar{P} \bar{P}$ is Failure to Maintain Proper Propulsion, FTMPC is Failure to Maintain Proper Configuration, and SMEDS is Simultaneous Dual SSME Premature Shutdown. 


\begin{tabular}{|c|c|c|c|c|c|}
\hline Stage \# & $\begin{array}{l}\text { Start Time } \\
(\text { sec })\end{array}$ & $\begin{array}{l}\text { End time } \\
\text { (sec) }\end{array}$ & Interval & Event & Description \\
\hline 1 & 0 & 0.3 & 0.3 & SRB Ignition & $\begin{array}{l}\text { SRBs ignite. The SSMEs are at } 100 \% \text { rated } \\
\text { power and gimbaled to launch position; all } \\
\text { connections with the vehicle retract or are } \\
\text { dropped }\end{array}$ \\
\hline 2 & 0.3 & & & Liftoff & The vehicle lifts of the pad \\
\hline 3 & 0.3 & 6 & 5.7 & Tower clear & $\begin{array}{l}\text { Make the necessary corrections to remain in } \\
\text { vertical flight }\end{array}$ \\
\hline $4^{*}$ & 6 & 10 & 4 & & \\
\hline \multirow[t]{2}{*}{5} & 10 & 18 & 8 & $\begin{array}{l}\text { Start roll } \\
\text { maneuver }\end{array}$ & $\begin{array}{l}\text { The Shuttle beings a roll program to achieve } \\
\text { a northeasterly track from KSC, heading } \\
\text { toward a } 51.6 \text { degree inclination to the } \\
\text { equator. }\end{array}$ \\
\hline & 18 & & & End roll & $\begin{array}{l}\text { The shuttle completes the programmed roll } \\
\text { maneuver and is now positioned heads down, } \\
\text { wings level. }\end{array}$ \\
\hline $6^{*}$ & 18 & 26 & 8 & & $x^{2}=$ \\
\hline \multirow[t]{2}{*}{7} & 26 & 30 & 4 & $\begin{array}{l}\text { Start throttle } \\
\text { down }\end{array}$ & $\begin{array}{l}\text { The three liquid-fueled main engines are } \\
\text { throttled down to } 72 \text { percent rated thrust to } \\
\text { ease the vehicle's flight through the dense } \\
\text { lower atmosphere. }\end{array}$ \\
\hline & 30 & & & $\begin{array}{l}\text { Throttle down } \\
\text { complete }\end{array}$ & \\
\hline \multirow[t]{2}{*}{$8^{*}$} & 30 & 60 & 30 & & \\
\hline & 60 & & & $\operatorname{Max} Q$ & $\begin{array}{l}\text { The maximum dynamic pressure reaches } 580 \\
\text { psf }\end{array}$ \\
\hline 9 & 60 & 64 & 4 & Throttle up & $\begin{array}{l}\text { Main engines begin throttling back up. The } \\
\text { engine's thrust level will be taken to } 104.5 \\
\text { percent. }\end{array}$ \\
\hline $10^{*}$ & 64 & 120 & 56 & & 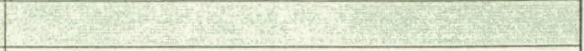 \\
\hline $11^{* *}$ & 120 & 126 & 6 & SRB staging & $\begin{array}{l}\text { Having consumed all their propellant, the } \\
\text { solid rocket boosters are jettisoned from the } \\
\text { attachment points on the external fuel tank. } \\
\text { The boosters parachute into the Atlantic } \\
\text { Ocean for recovery and reuse. }\end{array}$ \\
\hline
\end{tabular}

Figure 5. Representative events in the Space Shuttle's trajectory during the first 120 seconds. 


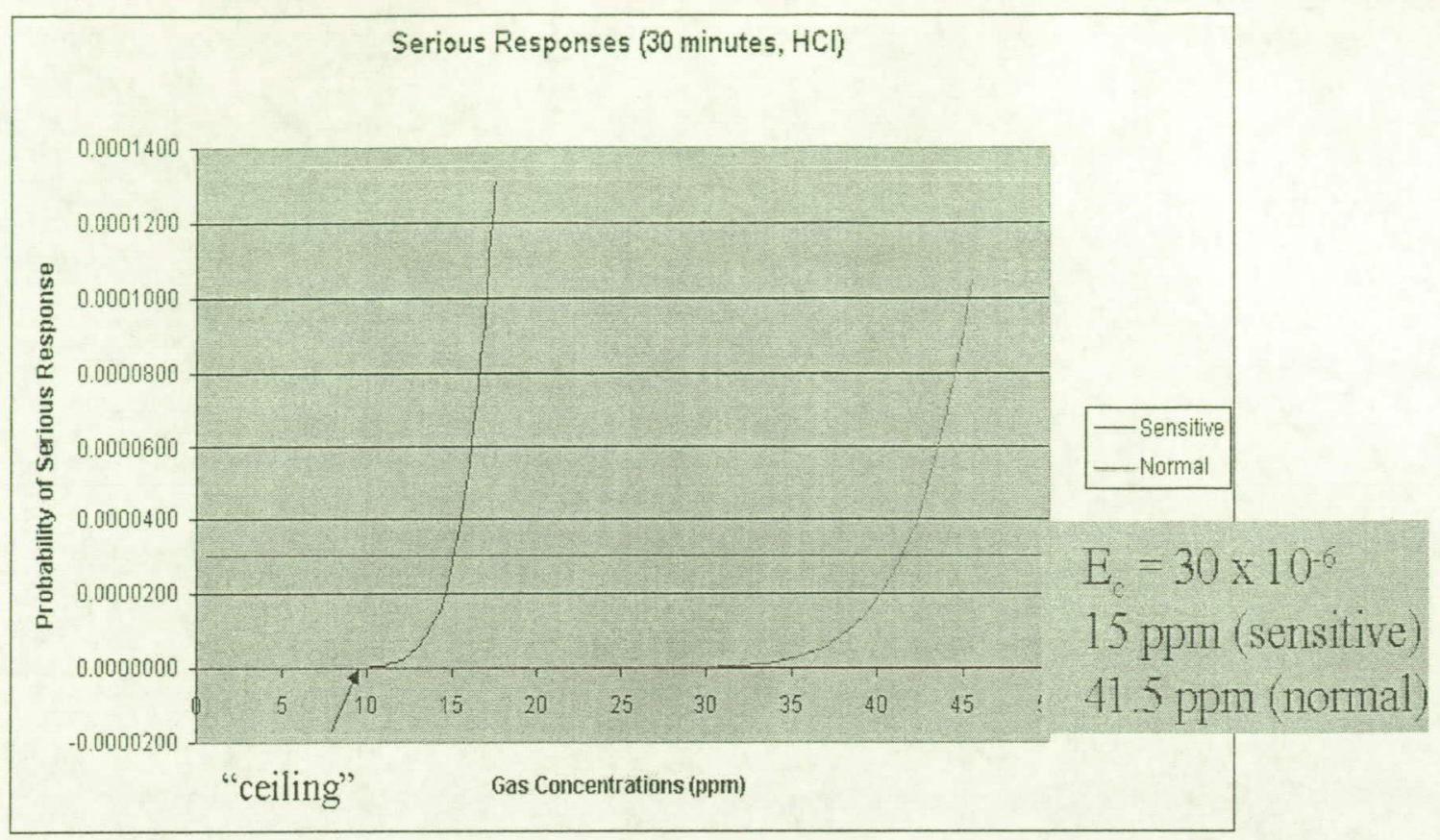

Figure 6. Exposure Response Function for $\mathrm{HCl}$. 


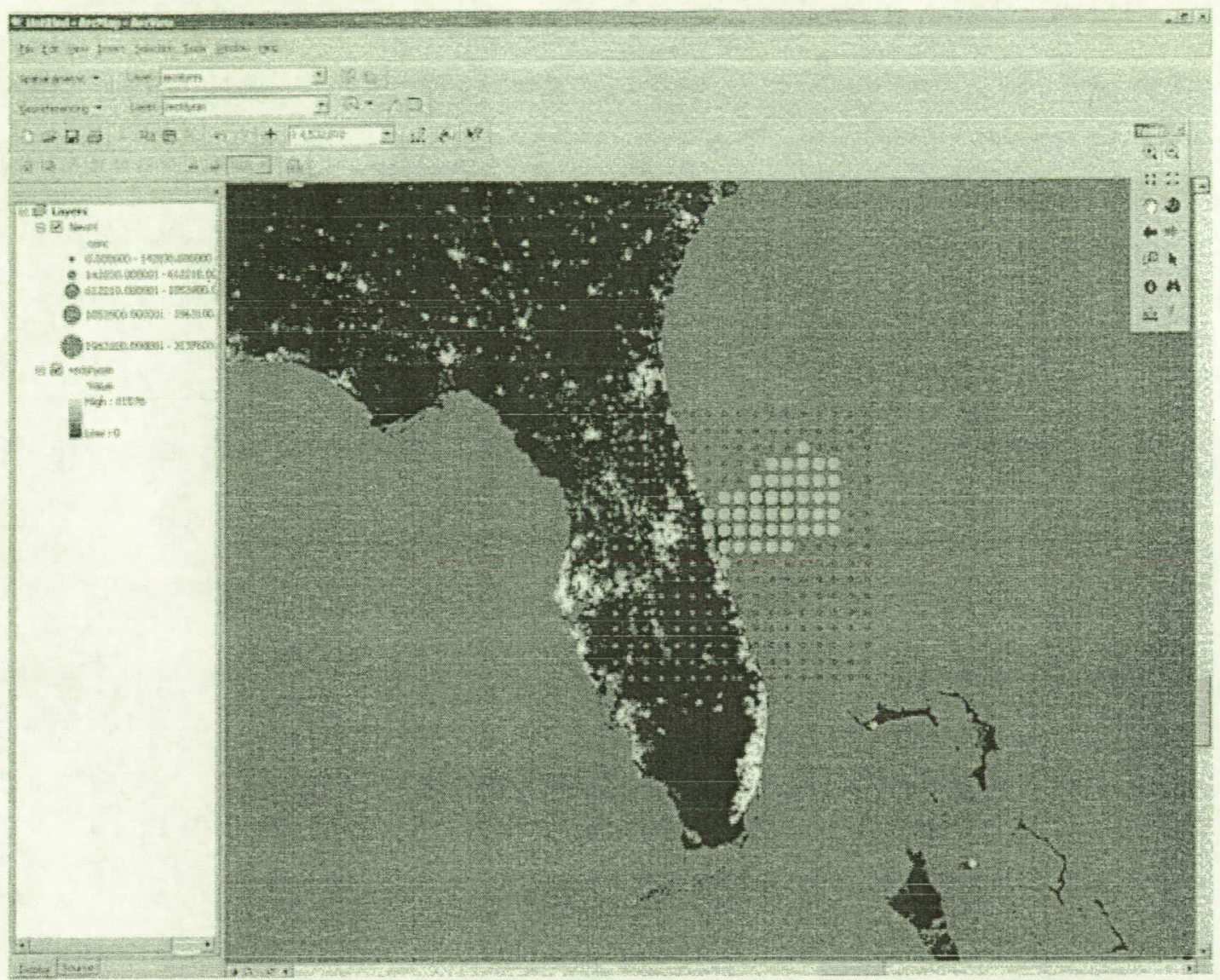

Figure 7. Exercising the Virtual Range system: Output of CALPUFF in ArcGIS from a simulated accident at 34 seconds with specific weather information of October 7, 2002 (2:46 p.m. Central Daylight Time) (Launch Date and Time of NASA Shuttle Atlantis, STS-112 (Space Transportation System - Mission 112)). 
Table I. Factors affecting $\mathrm{E}_{\mathrm{c}}$.

\begin{tabular}{|c|c|c|}
\hline Factor & Example & Range \\
\hline $\begin{array}{l}\text { Flight path's azimuth (direction of the } \\
\text { launch) }\end{array}$ & 1120 & $\begin{array}{l}\text { Polar: } 370-44 \text { o; ecuatorial: } 110 \\
\text { o-114o }\end{array}$ \\
\hline $\begin{array}{l}\text { Time of accident [seconds after launch] } \\
\text { (sets altitude and amount of pollutants } \\
\text { released) }\end{array}$ & 15 & $\begin{array}{l}0-120 ; \text { will try } 0,5,10,15,20, \\
25, \text { and } 30 \text { seconds. }\end{array}$ \\
\hline $\begin{array}{l}\text { Nature and amount of the released } \\
\text { toxicant (depends on initial value, flight } \\
\text { time, and consumption rate) }\end{array}$ & $\mathrm{HCl}, 8$ tons & Design and capacity of the SRBs \\
\hline Initial velocity of the gas plume & $\begin{array}{l}380 \\
\text { (CALPUFF's } \\
\text { default) }\end{array}$ & Needs further research \\
\hline Weather conditions & $4 / 8 / 2002$ & $\begin{array}{l}\text { As represented by } 5 \text { actual } \\
\text { launch dates }\end{array}$ \\
\hline Wind direction (f(altitude)) & 200 degrees & $\begin{array}{l}\text { Limits represented by angles } \\
\text { observed in actual launch dates }\end{array}$ \\
\hline Wind velocity (f(altitude)) & $10 \mathrm{~m} / \mathrm{s}$ & $\begin{array}{l}\text { Limits represented by speeds } \\
\text { observed in actual launch dates }\end{array}$ \\
\hline Critical concentration for the pollutant & $15 \mathrm{ppm}$ & $15-45 \mathrm{ppm}$ (from $\mathrm{ERF}$ for $\mathrm{HCl}$ ) \\
\hline $\begin{array}{l}\text { The proportion of exposed population } \\
\text { incapacitated or dead as a result of the } \\
\text { accident }\end{array}$ & $60 \%$ & 0 to $100 \%$ \\
\hline
\end{tabular}

